\title{
Short-term training of upper gastrointestinal endoscopy for resident doctors in Sotogahama Central Hospital in Aomori, Japan
}

This article was published in the following Dove Press journal:

Advances in Medical Education and Practice

9 July 2013

Number of times this article has been viewed

\author{
Takako Soma ${ }^{1,2, *}$ \\ Yuichi Sakamoto ${ }^{1,2, *}$ \\ Yasufumi Matsuoka',2 \\ Tomoko Nakano ${ }^{1,2}$ \\ Masatoshi Kamiuttanai' \\ Masaki Akiyama' \\ 'Department of General Medicine, \\ Sotogahama Central Hospital, Aomori, \\ Japan; ${ }^{2}$ Department of General \\ Medicine, Aomori Prefectural Central \\ Hospital, Aomori, Japan \\ *These authors contributed equally \\ to this work
}

\begin{abstract}
It is essential for young physicians in municipal hospitals to be familiar with the technique of upper gastrointestinal (GI) endoscopy. Endoscopy is an exciting subspecialty in primary care medicine. Endoscopic procedures are primarily performed by general physicians in Japan. However, a standardized strategy for teaching diagnostic GI endoscopy is still lacking, and there is not sufficient time for young physicians to effectively learn the upper GI endoscopy technique. To elucidate how young physicians can be trained in the skills of GI endoscopy in a short time period, we initiated a 12 -week training course. Two young physicians performed upper GI endoscopies for outpatients and inpatients 2 or 3 days a week from April 2010 to March 2012. The total number of cases undergoing GI endoscopy during the training course in each year was 117 and 111, respectively. The young physicians were trained in this technique by the attending physician. The short-term training course included four phases. During these phases, the young physicians learned how to insert the endoscope through the nasal cavity or oral cavity into the esophageal inlet, how to pass the endoscope from the esophageal inlet into the duodenum, how to take pictures with the endoscope, and how to stain the gastric and duodenal mucosa and take mucosal biopsy samples. The young physicians experienced 20-30 cases in each phase. In week five, they performed endoscope insertion into the duodenum along the folds of the greater curvature of the stomach. They viewed the entire stomach and took pictures until week ten of the course. The pictures taken in week ten were of a better quality for examining the disease lesions than those taken in week six. In the last 2 weeks of the training course, the young physicians stained the gastric and duodenal mucosa and took mucosal biopsy samples. The short-term training course of 100-120 cases in 12 weeks was effective for teaching young physicians how to perform GI endoscopies independently.
\end{abstract}

Keywords: endoscopy, gastroenterology, general medicine, medical education, young physicians

\section{Introduction}

It is essential for young physicians in municipal hospitals to be familiar with the technique of upper gastrointestinal (GI) endoscopy. Endoscopy is an exciting subspecialty in primary care medicine and gastroenterology. Endoscopic procedures are primarily performed by general physicians in Japan. There is not sufficient time for young physicians to learn the upper GI endoscopy technique because of their overloaded work schedules. Traditionally, young physicians have learned the GI endoscopy technique through on-the-job training conducted by the attending physician and have been evaluated by their supervisors in many hospitals in Japan. On-the-job training involving actual patients is stressful both for the patients and for the attending physician. ${ }^{1}$ As a method of GI endoscopy training that minimizes discomfort for the
Correspondence: Yuichi Sakamoto Department of Laboratory Medicine, Aomori Prefectural Central Hospital, 2-I-I Higashitsukurimichi, Aomori 030 8553, Japan

Tel $+8 \mid 177268$ III

Fax $+8 \mid 177261885$

Email 97036ys@jichi.ac.jp 
patient, computer-based endoscopic simulators have been useful in recent years. ${ }^{2,3}$ However, not all hospitals actually have these instruments.

Recently, it has been noted that clinical training of resident doctors in rural areas in Japan is more focused on general medicine. A number of young physicians enroll for study of regional medicine at our hospital annually. However, the number of physicians specializing in regional medicine in rural areas is still low; therefore, they are unable to teach young physicians the skills of GI endoscopy.

Sotogahama is located in Aomori Prefecture, in the northern part of mainland Japan. In 2011, the population of Sotogahama was approximately 7000 , including the elderly (37.7\%). Thus, it is difficult for a few attending physicians to teach the skills of GI endoscopy effectively to resident doctors. In Aomori, teaching the skills of GI endoscopy to resident doctors tends to be limited in some departments of gastroenterology. Therefore, to elucidate how young physicians can be effectively trained in the skills of GI endoscopy in a short time period, we experimentally initiated a 12-week training course.

\section{Materials and methods Patients}

Two young physicians performed upper GI endoscopies for outpatients and inpatients 2 or 3 days a week from April 2010 to March 2012. The total number of cases undergoing GI endoscopy during the training course each year was 117 and 111, respectively (Table 1). Endoscopic diagnoses excluding atrophic gastritis are shown in Table 1. We had informed consent from patients for young doctors to perform GI endoscopy on them. Some patients refused GI endoscopy performed by young doctors.

\section{Training}

A flowchart of this course is shown in Table 2. An attending physician with a board certification from the Japanese Endoscopy Association trained the young physicians. There were no theoretical sessions of GI endoscopy in this course. The short-term training course included four phases. In phase 1, the young physicians learnt how to insert the endoscope through the nasal cavity or oral cavity into the esophageal inlet. In phase 2, they learnt how to pass the endoscope from the esophageal inlet into the duodenum. The importance of inserting the endoscope into the esophagus along the axis of the esophagus and the folds of the greater curvature of the stomach was emphasized. In phase 3 , the young physicians took pictures with the endoscope. The pictures of the lesions
Table I Total cases and endoscopic diagnoses

\begin{tabular}{lll}
\hline & $\mathbf{2 0 1 0}$ & $\mathbf{2 0 I I}$ \\
\hline Total cases & 117 & $1 \mathrm{II}$ \\
Average/week & 9.8 & 9.3 \\
Biopsy cases & 12 & 20 \\
Diagnoses & & \\
Gastric ulcer & 16 & 9 \\
Duodenal ulcer & 4 & 9 \\
Esophagitis & 6 & 5 \\
Gastric cancer & & \\
$\quad$ Early stage & 7 & 6 \\
$\quad$ Progressive stage & 1 & 3 \\
Gastric adenoma & 2 & 5 \\
Gastric polyp & 10 & 12 \\
Erosive gastritis & 9 & 18 \\
Sliding hernia & 14 & 38 \\
Gastric submucosal lesion & 2 & - \\
Acute gastric mucosal lesion & 2 & - \\
Duodenitis & - & 2 \\
Duodenal polyp & - & 4 \\
Esophageal candidiasis & - & 5 \\
Telangiectasia & - & 2 \\
Intestinal metaplasia & - & 3 \\
\hline
\end{tabular}

were taken at an optimal angle. Instruction on taking pictures appropriate for use for consultations with other hospitals was also included in phase 3 . Taking continuous photos of the lesions in a direct manner was emphasized. In phase 4 , the young physicians learnt how to stain the gastric and duodenal mucosae and take biopsy mucosal samples.

The attending physician stood behind the young physician and guided the young physician while looking at the screen (Figure 1). In each case, the young physician was allowed to use the endoscope. If the endoscopy lasted more than 5 minutes, the attending physician performed the test instead of the young physician. The young physicians experience 20-30 cases in each phase. The duration of the

Table 2 Short-term training consisting of 12 weeks

\begin{tabular}{|c|c|c|c|}
\hline Step & Week & & $\begin{array}{l}\text { Number of } \\
\text { cases (average) }\end{array}$ \\
\hline I & $\begin{array}{l}1 \\
2 \\
3 \\
4\end{array}$ & $\begin{array}{l}\text { Insertion from the nasal cavity } \\
\text { and oral cavity to the esophageal } \\
\text { inlet }\end{array}$ & 30 \\
\hline 2 & $\begin{array}{l}5 \\
6 \\
7 \\
8\end{array}$ & $\begin{array}{l}\text { Insertion from esophageal inlet } \\
\text { to the duodenum }\end{array}$ & 40 \\
\hline 3 & $\begin{array}{l}9 \\
10\end{array}$ & Taking pictures & 20 \\
\hline 4 & $\begin{array}{l}11 \\
12\end{array}$ & $\begin{array}{l}\text { Training in gastric and duodenal } \\
\text { mucosa and taking biopsy mucosal } \\
\text { samples }\end{array}$ & 30 \\
\hline
\end{tabular}


A

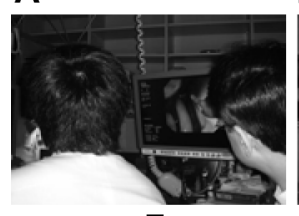

$\mathbf{F}$

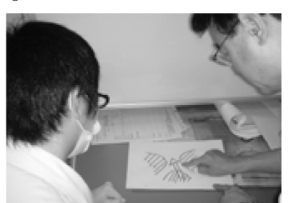

B

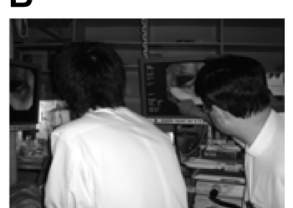

G

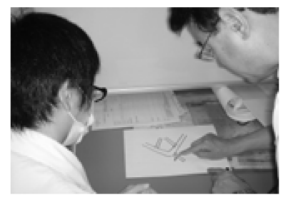

C

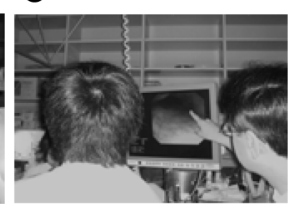

H

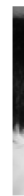

D

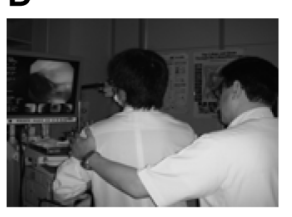

I

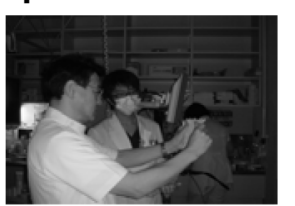

Figure I (A-I) Training scenarios. An attending physician points to the middle nasal concha (A); insertion into the esophagus (B); insertion into the esophagus along the axis of the esophagus (C); focusing on the greater curvature of the stomach (D); J-turn methods (E); feedback on the insertion in the middle nasal concha, using a schema (F); feedback on the insertion in the esophagus, using a schema $(\mathbf{G})$; feedback on focusing on the greater curvature, using a schema $(\mathbf{H})$; feedback on direct focusing, using cloth (I).

course was 12 weeks. After each endoscopy, the attending physician provided feedback to the young physicians. The young physicians then created an endoscopy report in consensus with the attending physician.

We used quick feedback before the GI endoscopy test. There were no assessment sheets or forms. The attending doctors asked each trainee how they felt or to assess their own skills of endoscopy, to which the trainee responded. The attending doctor taught important points and techniques. After that, they tried the next GI endoscopy. The attending doctor and young physicians were able to assess each other quickly. The physicians were too busy to have much time to discuss and study GI endoscopy with one another.

\section{Results}

The endoscopic diagnoses that the young physicians experienced are shown in Table 1. Differences in diseases did not affect advancement in this training. All trainees were satisfied with this program and their GI endoscopy skills achieved through the program. We had a similar training program in 2005; however we evaluated the experiences of only two trainees then. In another similar program in Sotogahama, begun in 2005, seven young doctors completed the course and acquired the skills to perform GI endoscopy tests by themselves. Both the young physicians in the program completed phase 1 in 2 weeks. Phase 2 was completed by week four. In week five, the young physicians inserted the endoscope into the duodenum along the folds of the greater curvature of the stomach. The young physicians viewed the entire stomach and took pictures (phase 3) until week ten. After completion of phase 3, the attending physician permitted the young physicians to perform the endoscopy independently. Pictures taken in week six were compared to those taken in week ten; the latter pictures were of a better quality for examining disease lesions than the former pictures (Figure 2). The attending doctor checked pictures that the trainees took and evaluated their GI endoscopy performance. In the last 2 weeks, the young physicians stained the gastric and duodenal mucosae and took biopsy mucosal samples. Twelve weeks later, the young physicians performed endoscopy independently, excluding the technique for
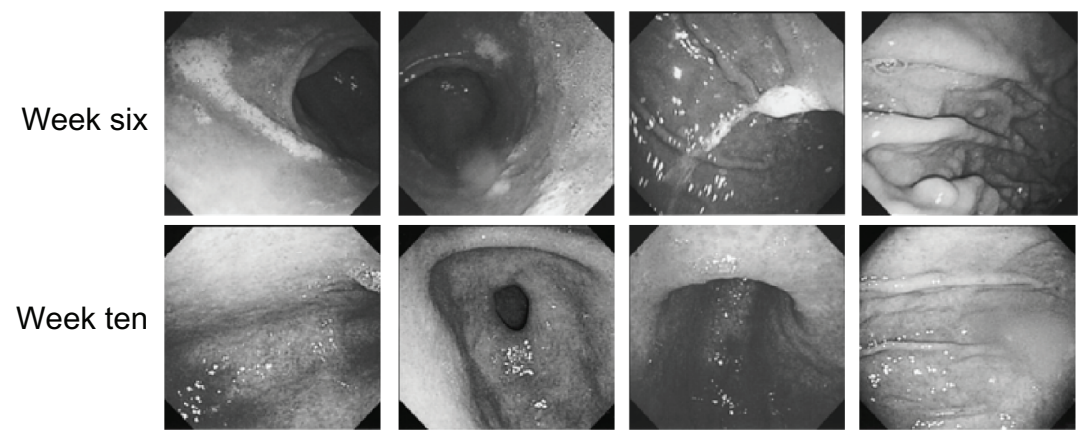

Figure 2 Comparison of pictures taken in week six with those taken in week ten of training. The pictures taken in week ten were of a better quality for checking disease lesions than the pictures taken in week six. The pictures taken in week ten were taken at a right angle. 
stopping bleeding. Twelve weeks is a relatively short period for young physicians to learn the skills of GI endoscopy.

The most difficult point in this course was inserting the endoscope along the folds of the greater curvature of the stomach in phase 2 . The young physicians became confused and unsure of where the scope was going. Gradually, the young physicians learnt endoscopic movement skills during endoscopy and through repeated feedback from the attending physician. The attending physician also performed the test when the young physicians had to do biopsy in phases 1-3 and when they required prompts during the procedure. There were no adverse events when young physicians performed GI endoscopy.

\section{Discussion}

The upper GI endoscopy technique is essential for general physicians practicing in rural areas in Japan. The location of the hospital where they learn the technique and the manner in which the technique is learnt affect the physicians' duration of learning and program in their places of employment. Our hospital receives sufficient diagnostic cases for the study of endoscopy. Thus, starting a short-term training course was feasible based on the daily work being performed in our hospital.

Our course is important for general medicine in rural areas in Aomori in Japan. Our course originally began to train young doctors of general medicine, not specialists of gastroenterology, and was limited within GI endoscopy technical training. The Training Committee of the American Society for Gastrointestinal Endoscopy suggested that a training course include not only study of GI endoscopy but also sigmoid colonoscopy, colonoscopy, endoscopic ultrasound, and therapeutic techniques. ${ }^{4}$ That training course is for specialists of gastroenterology within 3 years. Another report showed a training course for specialists in gastroenterology. ${ }^{5}$

Three important points were revealed in our training course. First, the establishment of a training course requires a sufficiently high number of cases, ample training time, and availability of attending physicians. Daily work makes it difficult to meet these requirements. It is necessary that the region and the hospital understand the importance of establishing a training course. If young physicians can perform endoscopies independently, a clinic's daily work progresses quickly and the clinic makes a greater contribution to the community.

A second important point is the attending physicians' passion for teaching and the young physicians' high motivation for mastering the endoscopy technique. The course is based on an obvious short-term goal, which encourages young physicians to perform GI endoscopy independently. For attending physicians, much time is needed for teaching, and this affects their daily work. However, once young physicians master the technique after 12 weeks, the daily work backlog can be completed.

The third important point is the establishment of a learning model. We established a short-term upskilling method (12 weeks). At the beginning of the course, clear goals presented every week made the young physicians highly motivated.

Kolb and Fry's learning style inventory is based on the individual. ${ }^{6}$ This method can be applied to learning the GI endoscopy technique. The trainees build their own theories by progressing through a cycle of accommodating, diverging, assimilating, and converging.

Accommodating involves active experimentation, such as performing the endoscopy. Diverging is a concrete experience, such as the failure or success of the test. After diverging, the young physicians analyze why they failed or succeeded, and the manner in which the attending physicians performed the procedure. Through reflective observation, the young physicians can take the step of assimilating. This step includes abstract conceptualization, wherein the learners generalize the conclusion obtained by reflective observation. In the converging step, active experimentation resumes. The learners can enter this cycle at any step.

Engels and de Gara reported that students predominantly learn through assimilating, whereas young physicians and attending physicians predominantly learn through converging. ${ }^{7}$ The difference in learning methods between young doctors and attending doctors was not significant. On the other hand, Jack et al reported that all students, young physicians, and attending physicians consider converging in the learning styles as important. ${ }^{8}$ Attending physicians significantly consider assimilating as well as converging in learning style as important. These findings can be explained by the fact that young physicians want to gain experience, whereas attending physicians believe that the construction of their own theories is important.

Our course is popular among young physicians and residents, because our hospital receives many GI endoscopy cases. However, repeating active experimentation and concrete experiences in daily work without reflective observation and abstract conceptualization could create a learning bias, and it takes the individual a long time to establish his or her own theory. Therefore, a more effective 
training course and the systematization of the course should be considered in the future.

Many physicians believe that a standardized educational strategy for diagnostic GI endoscopy is still lacking. There are few training courses for GI endoscopy for young doctors of general medicine. Textbooks of GI endoscopy do not have much explanation of strategy of training step by step. Ende et al reported that supplementation of clinical training in upper GI endoscopy with structured simulator training appears to be superior to clinical training alone; however, simulator training alone seems insufficient for improving endoscopic skills and developing a training strategy for diagnostic upper GI endoscopy. ${ }^{9}$

Our attractive program of upper GI endoscopy also takes advantage of recruiting new physicians in the rural areas. There is no certificate of completion. However, a lot of young physicians are interested in this program and come to our hospital. The training course was popular not only for young physicians in our hospital but also for residents that were receiving training in regional medicine in Aomori.

\section{Conclusion}

The short-term course of 100-120 cases in 12 weeks was effective in training young physicians to perform GI endoscopy independently. An attractive training program will lead to the greater recruitment of physicians specializing in regional medicine. Our training course was planned for the young physicians in our hospital. Unexpectedly, resident applications for training in regional medicine increased.
Increasing numbers of applicants will lead to the recruitment of more physicians in rural areas in the future.

\section{Acknowledgment}

We thank Motoki Ohnishi (Department of General Medicine, Aomori Prefectural Central Hospital) for his comments on this article.

\section{Disclosure}

The authors report no conflicts of interest in this work.

\section{References}

1. Hochberger J, Maiss J, Magdeburg B, Cohen J, Hahn EG. Training simulators and education in gastrointestinal endoscopy: current status and perspectives in 2001. Endoscopy. 2001;33:541-549.

2. Bar-Meir S. A new endoscopic simulator. Endoscopy. 2000;32: 898-900.

3. Di Giulio E, Fregonese D, Casetti T, et al. Training with a computer-based simulator achieves basic manual skills required for upper endoscopy: a randomized controlled trial. Gastrointest Endosc. 2004;60:196-200.

4. ASGE Training Committee, Adler DG, Bakis G, et al. Principles of training in GI endoscopy. Gastrointest Endosc. 2012;75:231-235.

5. Saraswat VA, Tandon RK. Gastrointestinal endoscopy training in India. Indian J Gastroenterol. 1999;18:167-173.

6. Kolb D, Fry R. Toward an applied theory of experiential learning. In: Cooper C, editor. Theories of Group Processes. New York: John Wiley and Sons; 1975:33-56.

7. Engels PT, de Gara C. Learning styles of medical students, general surgery residents, and general surgeons: implications for surgical education. BMC Med Educ. 2010;10:51.

8. Jack MC, Kenkare SB, Saville BR, et al. Improving education under work-hour restrictions: comparing learning and teaching preferences of faculty, residents, and students. J Surg Educ. 2010;67:290-296.

9. Ende A, Zopf Y, Konturek P, et al. Strategies for training in diagnostic upper endoscopy: a prospective, randomized trial. Gastrointest Endosc. 2012;75:254-260.
Advances in Medical Education and Practice

\section{Publish your work in this journal}

Advances in Medical Education and Practice is an international, peerreviewed, open access journal that aims to present and publish research on Medical Education covering medical, dental, nursing and allied healthcare professional education. The journal covers undergraduate education, postgraduate training and continuing medical education

\section{Dovepress}

including emerging trends and innovative models linking education, research, and healthcare services. The manuscript management system is completely online and includes a very quick and fair peer-review system. Visit http://www.dovepress.com/testimonials.php to read real quotes from published authors. 